\title{
Linked Color Imaging of Eosinophilic Esophagitis
}

\author{
Yasuhiko Abe ${ }^{1,2}$, Yu Sasaki ${ }^{1}$, Takashi Kon ${ }^{1}$ and Yoshiyuki Ueno ${ }^{1}$ \\ Key words: eosinophilic esophagitis, esophageal eosinophilia, endoscopic diagnosis, image-enhanced \\ endoscopy
}

(Intern Med 59: 1573-1574, 2020)

(DOI: 10.2169/internalmedicine.4381-19)


Picture 1.

A 74-year-old man with dysphagia underwent screening endoscopy. Characteristic endoscopic findings of eosinophilic esophagitis (EoE), such as furrows, rings, or exudates, were not clearly observed, but edematous mucosa was vaguely detected on white light imaging (Picture 1a). These areas were highlighted as a beige color area on blue laser imaging (BLI) (Picture 1b) and a yellowish area on linked color imaging (LCI) (Picture 1c, d). Intense eosinophilic infiltration was observed in these image-enhanced areas his- tologically, but no similar observation was made in the normal-appearing mucosa (Picture 2). This patient was ultimately diagnosed with EoE. A meta-analysis reported that $15 \%$ of adult patients have no characteristic endoscopic manifestations of EoE (1). BLI and LCI are newly developed endoscopic imaging technologies on which the visibility of various organic lesions, such as inflammation or tumors, is enhanced (2). These technologies may improve the diagnostic accuracy of EoE by increasing the visibility of

${ }^{1}$ Department of Gastroenterology, Yamagata University Faculty of Medicine, Japan and ${ }^{2}$ Division of Endoscopy, Yamagata University Hospital, Japan

Received: December 26, 2019; Accepted: January 23, 2020; Advance Publication by J-STAGE: March 19, 2020

Correspondence to Dr. Yasuhiko Abe, y-abe@med.id.yamagata-u.ac.jp 




Picture 2.

esophageal eosinophilia.

The authors state that they have no Conflict of Interest (COI).

\section{References}

1. Kim HP, Vance RB, Shaheen NJ, et al. The prevalence and diagnostic utility of endoscopic features of eosinophilic esophagitis: a meta-analysis. Clin Gastroenterol Hepatol 10: 988-996, 2012.

2. Osawa H, Miura Y, Takezawa T, et al. Linked color imaging and blue laser imaging for upper gastrointestinal screening. Clin Endosc 51: 513-526, 2018.

The Internal Medicine is an Open Access journal distributed under the Creative Commons Attribution-NonCommercial-NoDerivatives 4.0 International License. To view the details of this license, please visit (https://creativecommons.org/licenses/ by-nc-nd/4.0/).

(C) 2020 The Japanese Society of Internal Medicine Intern Med 59: 1573-1574, 2020 